\title{
No hay cuerpo sin imagen. Visualidad gay $y$ politica virtual en tiempos liberales
}

\author{
Cristian Cabello Valenzuela ${ }^{2}$ \\ Universidad de Chile, Santiago de Chile, Chile ${ }^{3}$ \\ cabelloperiodista@gmail.com \\ Recibido: 4 de diciembre de 2014 \\ Aceptado: 2 de mayo de 2015 \\ Disponible en línea: 30 de noviembre de 2015
}

1 Artículo de reflexión. Presenta el resultado de la investigación para optar por el título de Magíster en Comunicación Política. Agradezco a la investigadora feminista Alejandra Castillo su guía para esta investigación. En el artículo se enfatiza una perspectiva crítica feminista de la comunicación de la política sexual chilena en tiempos liberales.

2 Periodista y Magíster en Comunicación Política del Instituto de la Comunicación e Imagen (ICEI), Universidad de Chile.

3 Investigador asistente en el proyecto Fondecyt "Convergencia mediático tecnológica y vida cotidiana. Transformaciones socioculturales del Chile contemporáneo” del Departamento de Sociología de la Universidad de Chile (2014-2015). Es integrante del laboratorio de Cultura Mediática de la misma institución. 


\title{
No hay cuerpo sin imagen. Visualidad gay y politica virtual en tiempos liberales
}

\section{Resumen}

Este análisis visual revisa la publicidad política virtual de la organización homosexual Fundación Iguales durante el primer gobierno de derecha del Chile post-dictadura. Deteniéndose en distintos códigos de dispositivos audiovisuales, este artículo reconoce la construcción simbólica, afectiva y corporal a través de la cual se presenta una ciudadanía homosexual en redes sociales. Interesa reconocer cómo las estrategias audiovisuales políticas han facilitado un ingreso receptivo de 'lo homosexual' en la política neoliberal chilena. Se describe la producción de sentido que otorga legitimidad y no rechazo a la representación del nuevo ciudadano gay y qué imágenes audiovisuales realizan esta validación de lo homosexual. Finalmente, se realiza una crítica a los discursos políticos de la tolerancia y la igualdad que resguardan la construcción de narrativas politicas a favor de la diversidad sexual bajo consignas comunicacionales liberales.

Palabras claves: visualidad; liberalismo; virtual; gay; ciudadanía

\section{No body without image. Gay visual and virtual politics in liberal times}

\begin{abstract}
This visual analysis reviews the virtual political advertising of the homosexual organization Fundación Iguales (Equals Foundation) during the first right wing government in Chile post-dictatorship. Analyzing different codes in audiovisual devices, this article recognizes the symbolic, emotional and physical construction through which homosexual citizenship appears in social networks. It is interested in recognizing how political audiovisual strategies have provided a receptive income of 'the homosexual' in Chile's neoliberal policy. It is described the production of meaning that grants legitimacy and no opposition to the representation of the new gay citizen as well as the visual images that contributed to the validation of homosexuality. Finally, it is made a review of the political speeches on tolerance and equality that defend the construction of political narratives in favor of sexual diversity under liberal slogans.
\end{abstract}

Keywords: visuality; liberalism; virtual; gay; citizenship

\section{Não há corpo sem imagem. Visualidade gay e politica virtual em tempos liberais}

\section{Resumo}

Esta análise visual revisa a publicidade política virtual da organização homossexual Fundación Iguales durante o primeiro governo de direita no Chile pós-ditadura. Suspenso em diferentes códigos de dispositivos audiovisuais, este artigo reconhece a construção simbólica, afetiva e corporal através da qual ocorre uma cidadania homossexual nas redes sociais. Interessa reconhecer como as estratégias audiovisuais politicas facilitaram uma entrada receptiva de 'o homossexual' na politica neoliberal chilena. Descreve-se a produção de sentido que concede legitimidade e não rejeita a representação do novo cidadão gay e quais imagens audiovisuais realizam tal validação do homossexual. Por fim, realiza-se uma crítica dos discursos políticos de tolerância e igualdade que resguardam a construção de narrativas politicas em favor da diversidade sexual sob consignas comunicacionais liberais. Palavras-chave: visualidade; liberalismo; virtual; gay; cidadania 


\section{Introducción}

No hay liberación sin electrodomésticos.

Avital Ronell en Reinas de la Noche

En 2011, el surgimiento de la Fundación Iguales generó un quiebre en el escenario politico gay en el Chile post-dictatorial. Se trataba del primer grupo politico de diversidad sexual no relacionado con la izquierda o la centro-izquierda política, liderada durante casi veinte años por el Movimiento de Integración y Liberación Homosexual (Movilh). Fundación Iguales desplazó estos grupos creando nuevas e innovadoras estrategias y posicionamientos político-discursivos. Un ejemplo de ello fue la Marcha por la Igualdad que, a mediados del 2011, logró llenar la arteria principal de Santiago de Chile de personas homosexuales y heterosexuales, que apoyaban la campaña A Favor del Amor, difundida a través de redes sociales y medios de comunicación. También debe tenerse en cuenta la gran empatía que suscitaba su lider, Pablo Simonetti, y las exitosas campañas virales que se volvieron propaganda política obligatoria y de gran influencia en redes sociales, en una sociedad que se construye y narra a sí misma como la más tolerante, históricamente, frente a las sexualidades tradicionalmente conocidas como minoritarias.

La propaganda político-comunicacional de esta ciudadanía sexual comenzó a ser visibilizada y aceptada por la sociedad chilena en un contexto político que coincidió con el primer gobierno de derecha elegido tras la dictadura 4 . Las marchas masivas, la legitimación de un discurso políticamente correcto, centrado en la tolerancia y la participación activa en la agenda mediática de actores integrantes de esta política gay, hacen parte de una problemática que se investiga a partir de la sobre-representación de la ciudadanía gay en discursos visuales de circulación mediática. Todo esto se contrapone a los derechos sexuales aún no ganados y a las violencias de exclusión real contra personas no-heterosexuales.

4 Podemos denominar ampliamente como post-dictadura al período que, en Chile, marca el final del régimen militar, luego de 1989. Sin embargo, también podriamos hablar de post-transición después de 2011, que marca un nuevo ciclo político que visibiliza el tiempo posterior a la transición democrática chilena, marcada por la llegada de Sebastián Piñera al poder. 


\section{Homosexualidad, nación y mercado}

Lo relevante de estas campañas virales es que -además del éxito que tuvo la instalación del matrimonio homosexual en las agendas politicas y el gran número de personas que convocan sus marchas-implican un cambio estético y discursivo en lo que refiere a campañas vinculadas a los sectores de diversidad sexual. Este nuevo concepto, que presenta una 'homosexualidad liberal', plantea un quiebre en la forma y el contenido de los abordajes del tema que se han dado históricamente en la esfera pública chilena.

En la última década, las investigaciones en torno a 'lo gay' señalan lo controversial de un objeto de estudio que ha mutado en sus estrategias y significaciones políticas a partir de la normalización e institucionalización de sus prácticas activistas (Butler, 2010; Halperin, 2007b; Brown, 2006; Sabsay, 2011; Galindo, 2014). Se reconoce una actual despolitización de la identidad gay, atravesada por campos de mercantilización que han absorbido su potencial político, un campo politico conflictivo donde perspectivas feministas denuncian el pink washing, el blanqueamiento o el uso institucional que se hace de estas minorias por parte del Estado.

El pink washing sirve para describir "la posición de gobiernos represores que se alimentan de una fachada gayfriendly que, a veces, tiene un anclaje real, y otras veces no" (Bennet, en Curia, 2013). La política gay se instala como tema-país en los medios de comunicación y en la publicidad política, lo que implica un desplazamiento de los movimientos gay, desde los márgenes hasta la confirmación de una representación homo-nacionalista (Puar, 2007). El debate de las ciudadanías sexuales en Europa y Estados Unidos adquiere este carácter nacionalista. En estos casos, se describe "la emergencia de una homosexualidad nacional [...] que opera como un guión regulatorio" (Puar, 2007 , p. 2), con valores patrióticos sobre una nueva ciudadanía gay. En el presente trabajo se pretende revisar el blanqueamiento o higienización de las representaciones políticas gay en el caso chileno.

Blanco (2013) describe acertadamente el rol del ciudadano gay en el caso de la Fundación Iguales, afirmando que "[n]o se trata ya del 
reclamo del individuo al ejercicio de su propia sexualidad, sino el del ciudadano apartado de la comunidad de pertenencia exigiendo su derecho a ser regulado dentro del Estado". Sin embargo, no comparto las visiones que buscan simplemente aplicar esquemas de la teoría queer norteamericana para reproducir las esperanzas politicas en complicidad con esta política gay de elite:

Gracias a la gestión ejecutiva de Andrés Soffia V., la Fundación [Iguales] en su segundo año de funcionamiento ha virado a abrazar una política de defensa y regulación dentro del paradigma de los derechos humanos haciéndose eco de los estudios queer transnacionales [...] Soffia claramente entiende la importancia de las vidas queer en una región donde todavía las desigualdades estructurales definen mucho de la dinámica del mundo social. (Blanco, 2013)

¿Acaso la política queer incidirá en la mejora de la política ciudadana homosexual? Desconozco el fundamento y la fuente de estas afirmaciones que terminan por volverse cómplices del poder, al no reconocer las dificultades que cotidianamente viven las personas no-heterosexuales, y en las que no se tiene claro que, a nivel local, una vida queer en Latinoamérica no es lo mismo que una vida gay, homosexual o transexual. No se debe confundir o idealizar los discursos del Sur si simplemente hablan el mismo lenguaje que el Norte, como es el caso de la agenda global de la política gay de Fundación Iguales.

Son diversas las agencias sociales y comunicacionales que se movilizan en torno a una política gay, donde no solo importa la fuente de producción sino también todos los actores sociales e institucionales que hacen parte de una politica social contra la desigualdad. En este sentido, Chile aparece como la promesa conservadora y neoliberal de Latinoamérica, el país pequeño donde las lógicas económicas neoconservadoras rigen el espacio político y la actividad social. Es este país abierto al mercado el que tiene ahora el deber de demostrar la constante modernización o primer-mundización de su política. Las políticas de regulación se enfocan de modo individualista, y no ya a través de movimientos sociales. Se genera un tipo de individualización o, incluso, una personificación de la política. La figura del nuevo 
ciudadano liberal, el sujeto de estas democracias nacientes e imperfectas, se confunde con la figura del consumidor. Nos encontramos ante una visión "típicamente liberal de una pluralidad de intereses que se pueden regular sin necesidad de una instancia superior de decisión politica en que se evacue la cuestión de la soberanía" (Mouffe, 1999, p. 76). De este modo, la presencia evidente del gobierno se hace innecesaria, ante una política que aborda conflictos sociales como 'intereses privados'.

Proponemos que el neoliberalismo chileno rige los movimientos gay. Sus reglas o paradigmas son el marco que posibilita estas democracias sexuales imperfectas. En el caso latinoamericano, este neoliberalismo vuelca a las sociedades a:

[...] una idea de estructura social (la idea de que el mercado está por sobre la sociedad), como una concepción antropológica (el socialismo y todas las acciones comunitarias basadas en lazos de solidaridad representan estadios inferiores de la evolución social y son, por lo tanto, expresión de barbarie); un ideal de familia (la familia nuclear tradicional) y una valoración social de la división social del trabajo. (Garretón, 2012, p. 31)

El mercado es entonces el marco donde se expresa una política oficial en el Chile del siglo XXI. Un mercado que interviene las representaciones comunicacionales donde nadie parece ser dueño o responsable de su funcionamiento, donde ya no existe un poder a quién demandar las exclusiones que existen en el espacio público, sino donde las estrategias de impacto o sensibilización social, que permitirán el reconocimiento de grupos sociales como las minorías sexuales, son nuevas.

En Chile, el neoliberalismo avanzado (Ruiz y Boccardo, 2013) y las politicas de represión social que son herencia de la dictadura han dificultado la emergencia de movimientos sociales y resistencias políticas en contra de la gran desigualdad económica que se presenta en el país. Es la paradoja de un movimiento homosexual que se representa de modo positivo en el mercado de las imágenes políticas chilenas, tanto a través de redes sociales como de medios de comunicación 
periodísticos tradicionales; una ciudadanía gay que se instaló como un significante no conflictivo para los valores liberales. La visibilidad de los discursos de una política gay actual no se corresponde con un neoliberalismo que reprime y excluye de los regímenes de verdad a lo político, ubicado por fuera del mercado.

\section{Investigar las imágenes políticas}

La propaganda comunicacional mediática se presenta como objeto de estudio, con miras a comprender la excepcional visibilidad actual de un movimiento social y a entender las normas de la aceptación pública de un discurso político homosexual en tiempos liberales. Las imágenes, los videos virales para redes sociales y las intervenciones en prensa son los objetos visuales que dan cuenta de la dimensión publicitaria de la ciudadanía gay y sus usos de la comunicación que legitiman positivamente estos discursos que antes eran parte de lo prohibido. Me interesa la conformación de un corpus representativo de una cultura visual de la propaganda homosexual liberal, donde estos objetos comunicacionales y su relación con la sociedad generan transformaciones que median una integración a los regímenes de visibilidad de la identidad gay. De hecho, a partir de Bal (2003), podemos afirmar que la política gay nacionalista se caracteriza por un eminente aspecto visual: imágenes de personas gay saludando a ministros y presidentes, los testimonios públicos sobre una infancia victimizada y los conflictos religiosos en torno al matrimonio gay, todos ellos parte de los aspectos que se realzan visualmente y en los que lo visual aparece como "una propiedad relativa al propio objeto" (p. 24), instaurado por una ciudadanía gay mediáticamente situada. Retomo los spots de imagen (spots, fotografias publicitarias, etc.), donde la imagen política se entiende como "publicidad que hace referencia al ethos o fuente de credibilidad del candidato, como aquellos que destacan los atributos, rol, personalidad o carácter" (Chihu, 2010, p. 16).

Al destacar la dimensión visual de esta sexualidad, sobresale una comprensión donde no hay cuerpo sin imagen, es decir, donde las 
imágenes hacen posible la emergencia de los cuerpos sexuales. La visión que hay sobre el otro trae consigo percepciones sociales -estereotipos sobre las identidades sexuales-, nudos afectivos y conflictos políticos. Es en esta circulación de imágenes hegemónicas donde la comunicación refuerza los usos y sentidos que movilizan políticas que no se distancian demasiado de lo permitido por el Estado nación. Me interesa el modo en que las producciones comunicacionales hacen eco en la materialidad de los agenciamientos sociales de una política sexual.

El presente campo de investigación requiere el conocimiento de las dimensiones visuales en las que intervienen los relatos políticos y afectivos-sensibles de las imágenes. Se analiza una propaganda política homosexual contemporánea en la que las emociones y la producción de sensaciones de afecto son más importantes que las propuestas o convicciones de un habla politico afirmativo, donde el discurso político de las 'ideas' queda desplazado por unos discursos políticos de la afectación y la generación de amistades políticas virtuales.

Para investigar la dimensión afectiva de las imágenes, abordaré el caso del charming gay a partir del análisis de la propaganda comunicacional y política de la Fundación Iguales. Analizaré el rol del cuerpo y la configuración de la identidad gay en las representaciones comunicacionales de la Fundación Iguales. Hablo de gay y no de homosexual, para reforzar la dimensión publicitaria y el aspecto visual de una identidad que se distancia de una política radical: "gay y lesbiana se utilizan más precisamente para referirse a los individuos homosexuales que asumen con cierto grado de publicidad su orientación sexual" (Pecheny, 2002, p.127). Se trata de la conformación mediática de un ciudadano gay que se hace público y que, al mismo tiempo, impone regulaciones para comprender y comunicar esta subjetividad política. En otras palabras, se trata de un ciudadano gay más aceptado, lo que transgrediría el velo del secreto en el que se mantiene esta sexualidad. Sin embargo, ¿qué identidad homosexual es aceptada en los relatos comunicacionales públicos en el Chile reciente? La masculinidad de esta ciudadanía gay, como característica de la subjetividad politica analizada, hace parte de los resultados que se destacan en 
este análisis, que se concentró en la personificación y la forma que toma el sujeto homosexual en los discursos de una ciudadanía aprobada por los gobiernos y diversos grupos políticos hegemónicos, de forma transversal, en Chile.

No ha sido la lucha contra el VIH/sida y tampoco el movimiento social activo y de protesta homosexual los que han generado el reconocimiento político del ciudadano gay. Mi hipótesis plantea que es el marco económico y social de regulaciones neoliberales el que hace posible el reconocimiento legítimo de una política gay, restringida y enmarcada por modos de vida y valores liberales transmitidos a través de diversas tecnologías comunicacionales. Propongo que es el imaginario económico liberal nacional el que se proyecta y consolida, buscando demostrar su flexibilidad y progresismo a través del ingreso de 'lo gay' en la politica y que es una sociedad adecuada a las agendas globales de no discriminación contra homosexuales. De este modo, la estrategia comunicacional sirve para evidenciar una estabilidad política y social que busca afirmar un buen trato con los movimientos ciudadanos que ven en lo gay un caso ejemplar -a diferencia de lo que sucede con los movimientos sociales estudiantiles-. Como plantea la investigación social sobre homosexuales, "la sociedad parece tolerar mejor la sexualidad homosexual practicada en privado que el amor homosexual que se manifiesta públicamente" (Pecheny, 2002, p. 131), apuntando a las modificaciones liberales de un modo regulado de ejercer y comprender la política gay.

\section{Politica virtual: "te apoyo... pero no soy homosexual"}

En el siguiente apartado se abordan, a través de un análisis visual, dos campañas audiovisuales que la Fundación Iguales puso a circular entre 2011 y 2012. La primera, titulada “¿Estás a favor del amor?” (30 segundos de duración), buscaba posicionar el matrimonio homosexual, mientras que la segunda (49 segundos) buscaba motivar la participación en la "Marcha por la Igualdad". Ambos spots fueron 
realizados por la Fundación Iguales y narran la historia de aceptación y apoyo de parte de una persona hacia su familiar gay. Este espacio político amoroso, a través de distintas estrategias comunicacionales, logró rápidamente movilizar, en 2012, a más de cincuenta mil personas en una marcha a favor de la igualdad, apoyada por la difusión en prensa y televisión (aparición en matinales o noticieros).

¿Cómo 'lo homosexual' comenzó a ser valorado positivamente? ¿Cómo una identidad considerada 'delito' hace menos de trece años pasa a ser un signo beneficioso para la política heterosexual, más aún en el contexto de un gobierno de derecha y regido por valores familiares? Los spots de la "Marcha por la Igualdad" de la Fundación Iguales (2012) motivan el apoyo de la comunidad heterosexual a movilizarse ciudadanamente a favor de los homosexuales. La homosexualidad, en ambos spots, es llevadera, tranquila, habita sin tantos tropiezos el 'hoy', es de clase media-alta, y está tecnologizada; es una politica light que sella un modo liberal de habitar la política.

La puesta en escena visual protagoniza una estructura heterosexual, donde se asume el problema público de la homosexualidad, siendo la visualidad masculina una ayuda para su normalización. El punto de partida de Stella Bruzzi en su texto Men's Cinema (2008) es fundamental para entender esta situación: el problema de la sexualidad en relatos audiovisuales reconoce la relación entre masculinidad y visualidad, donde la política siempre se asocia a narrativas masculinas. La visualidad de la sexualidad no es, como bien señala Bruzzi, el estudio de "la representación del hombre en la pantalla" (Bruzzi, 2008, p.151). Lo que nos interesa es "cómo la puesta en escena siempre $[\ldots]$ está siendo usada para expresar temas de la masculinidad" (p.152). Lo masculino en lo audiovisual no será ya algo que esté 'dentro' del relato audiovisual y que no afecte sus códigos y estilos, sino que la estética de lo visual produce un sentido político del género.

Este problema ya lo describió también la feminista Teresa de Lauretis, cuando señaló que en los análisis sobre género "no se pone en duda la inscripción de la diferencia sexual en la[s] imagen[es]" (De Lauretis, 1992, p.41). Lo anterior explica por qué el presente 
análisis de lo visual no se reduce a una lectura sobre el género. La artista Martha Rosler (2007), en su texto recopilatorio Imágenes públicas, cuestionó la comprensión de la imagen como la búsqueda de un reconocimiento de cierta identidad por sobre la atención en la producción de la visualidad. Para Rosler, seguir esta línea mecánica de la sexualidad "presupone que las identidades -o roles y las experiencias- en cuestión son reconocibles (campesinos, travestis, negros) y fácilmente singularizables (peruano, americano, pobre), o bien presuponen una jerarquía dentro de la individualidad". (Rosler, 2007, p. 254). No basta con identificar y celebrar la inclusión de una identidad sexual en la pantalla o prensa, siendo que este modo de analizar las imágenes no permite comprender los movimientos y transformaciones del cuerpo político gay, un sujeto que se adapta a los contextos de un régimen de representación específico. No basta con mirar a alguien para determinar su género. No basta la apariencia para determinar si se es hombre, gay y/o feminista ${ }^{5}$.

¿Cuál es el espacio de este cuerpo gay? El lugar que ocupa el sujeto gay es un asunto político, en tanto que la homosexualidad se expone a regulaciones y constantes vulnerabilidades en el espacio público ${ }^{6}$. La arquitectura visual donde se ubica la sexualidad ha sido denominada por Beatriz Preciado como "pornotopia (Preciado, 2010). Las relaciones entre espacio y homosexualidad son sintomáticas, y esta última tiende a ser problemática. La homosexualidad es estereotipada a través de la hipersexualización de los espacios que circulan en el imaginario espacial de lo homosexual -discos, saunas, prostitución, etc.-. Quizás sea por esto que no hay mucho contacto entre cuerpos en estos spots: la pareja lésbica se toma las manos una sola vez; el hermano de una persona gay se limita a tocar la pantalla -y no a su hermano.

5 “¿Será mujer?, ¿'será hombre?, ¿será gay?, ¿será lesbiana?, ¿será bisexual?, ¿'será trans?”, se pregunta la filósofa feminista chilena Olga Grau, poniendo en duda la fortaleza de la categorización de género a partir de la fisionomía: "Esas preguntas también dan razón de la existencia y expansión de las políticas de desgenerización que han cobrado una dimensión corporal muy visible. La duda en las preguntas señaladas hace indudable la evidencia de las transformaciones que se han operado en los trazos identitarios" (Grau, 2011). La desviación de la mirada, más que una politica de la identidad afirmativa, aparece como una respuesta crítica a una mirada científica que clausura las posibilidades de la sexualidad en sus mismas categorizaciones indentitarias.

6 Traigo a colación el caso del joven homosexual Daniel Zamudio, asesinado a golpes por grupos de neonazis en el centro de Santiago, en marzo de 2012. Este acto sucedió en medio del surgimiento de la Fundación Iguales y posibilitó la visibilización de diversos discursos sobre lo homosexual. 
En el spot de 2012, el protagonista no es el personaje homosexual; es el hermano heterosexual. De inmediato, entre los recuerdos y flash-backs del video, el espectador es alertado sobre la existencia de una masculinidad delimitada, mediante la aparición anecdótica de una mujer -pareja del hermano- y a través de la autoridad de aquel que dice quién es gay

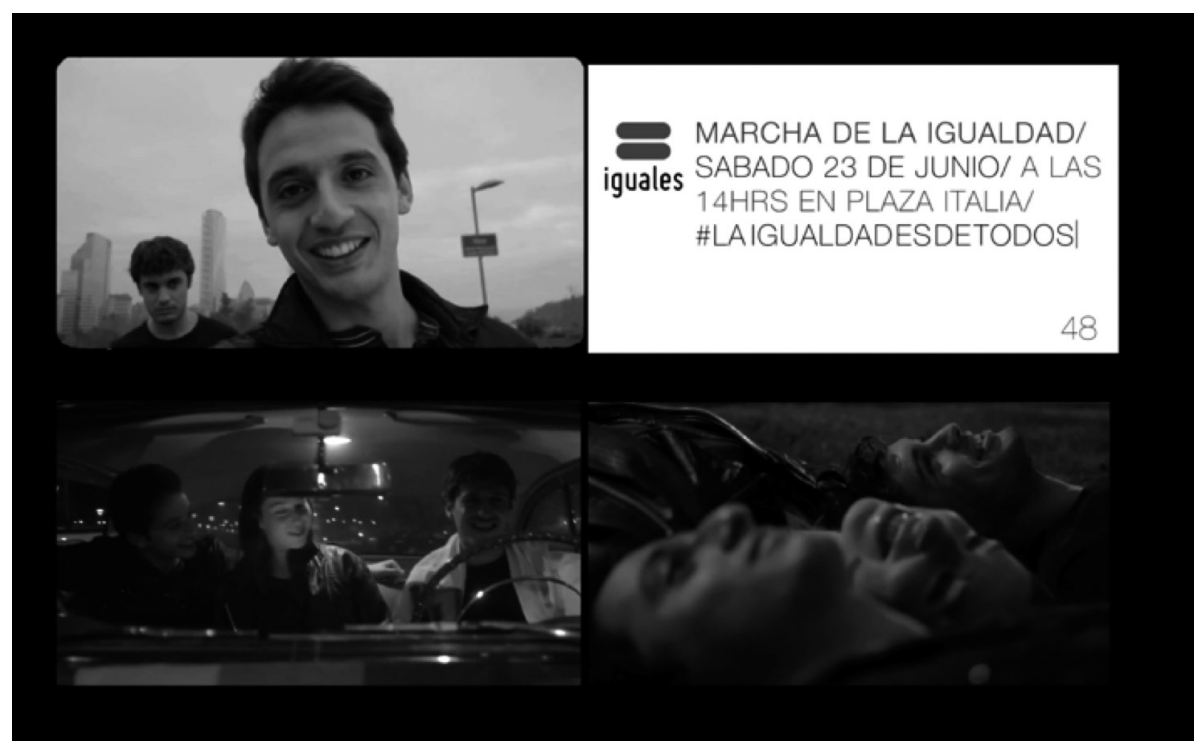

Figura 1. Cuatro láminas pertenecientes a spots para internet de la Fundación Iguales "Él es mi hermano; es gay", afirma el protagonista, realizando una acción declarativa que, por negación, afirma la heterosexualidad, marca una distancia y, por tanto, define la masculinidad. Se trata de lo que Stella Bruzzi llama "el miedo a la homosexualidad" (Bruzzi, 2008, p. 163), que definiría "muchas representaciones culturales de la masculinidad". Este audiovisual político-publicitario, aun cuando se asume como un gesto político positivo que ayuda a 'sacar del clóset' una sexualidad -y a pesar de que su intención sea la 'aceptación' e integración de 'lo homosexual'- envía el mensaje de que es una sexualidad que afecta emocionalmente a la comunidad heterosexual, pero que no la infecta, en el momento en que muestra 'lo homosexual' como algo natural. 
En la organización de la imagen se señala también el orden de lo familiar. Se observa un plano de seguimiento -al interior de una casa o al interior de un paseo familiar en un parque- que, al evitar interrupciones o inserciones de imágenes de otros lugares, busca representar una cotidianidad, una normalidad de lo íntimo. Este dispositivo visual, por ende, coopera en la construcción del sentido de normalidad liberal de la sexualidad: los hermanos caminan por un parque durante un atardecer en un paseo grato, 'normal' y cálido, conversan en el pasto, juegan con su mascota, salen juntos de paseo en el auto, 'hacen familia'

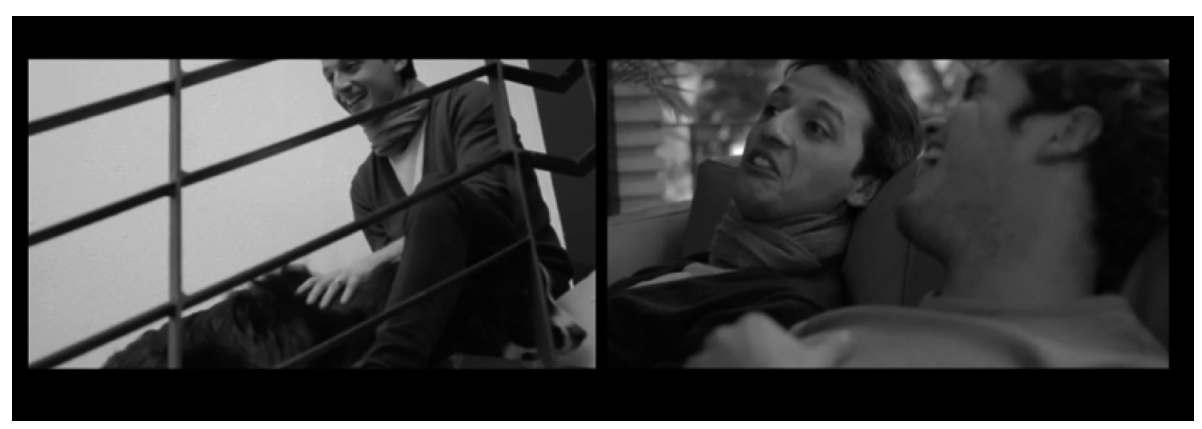

Figura 2. Dos láminas pertenecientes a spots de la Fundación Iguales

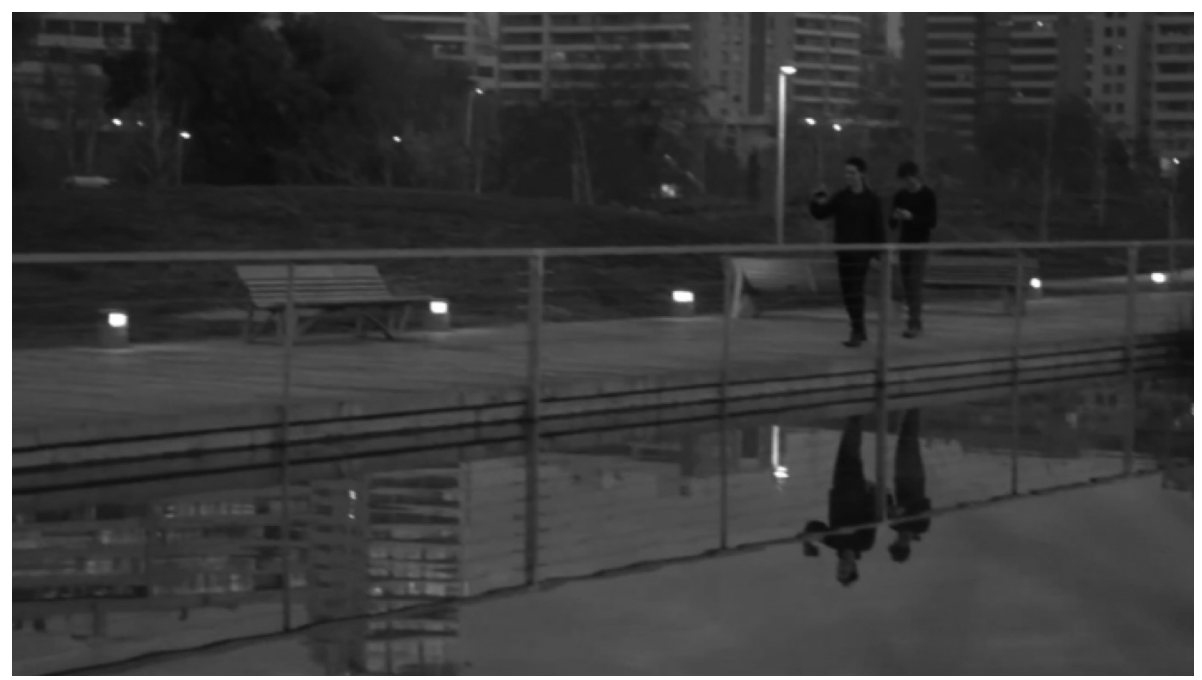

Figura 3. Lámina perteneciente a spot para internet de la Fundación Iguales 
Las propuestas audiovisuales-políticas de la Fundación Iguales 1ogran un giro liberal estratégico al exhibir la sexualidad homosexual a través de videos dirigidos al público o a la ciudadanía 'heterosexual', a quienes busca apelar a través de redes como YouTube. Se trata de familias, amigos y todos quienes se sientan parte de una política 'otra', ya no tan apegada a valores tradicionales. Al separar tan bien los espacios entre el espectador y el espectáculo homosexual y, asimismo, al no existir un deseo homosexual expresado, se imposibilita una identificación con este deseo homosexual.

Recordemos la tradicional vergüenza -que aún perdura- que produce el apoyo heterosexual a 'lo homosexual'. Cada vez un sujeto heterosexual hable por/sobre lo no-heterosexual corre el riesgo de perder su privilegio sexual -más aún si se trata de un hombre-. Esta política virtual, que logra posicionarse en internet y redes sociales -y que desde ese espacio empieza a mediatizarse- permite actuar sin la necesidad de hacerlo 'realmente' y, así, evita "la ansiedad relativa a la actividad en la verdadera realidad (en el espacio virtual), puedo hacerlo, puesto que sé que no lo estoy haciendo realmente, la inhibición o la vergüenza están suspendidas" (Zizek, 2007, p. 157). No hay peligro, no hay amenaza a la heterosexualidad familiar por parte de esta homosexualidad; lo que se dibuja en este ejercicio de una política virtual de lo homosexual -una politica que se comparte en la red- es una producción de una política que no amenaza un orden. El espectador-ciudadano aún se encuentra resguardado.

Si la condición de 'espectacularidad' es entendida como la combinación de dos dimensiones que generan la "producción del acontecimiento [político]: la del hecho mismo y la de su condición de noticia" (Richard, 1998, p.228), en el espacio virtual -vía por la cual circulan estos spots- no aplica esta búsqueda de espectacularidad atractiva como noticia, sino que, además de asegurar la credibilidad -es decir, la condición de hecho-, se hace urgente afectar y generar sensibilidades específicas sobre la homosexualidad. Se permite que el usuario/ twittero/ciudadano también se sienta parte de una politica otra, una política 'alternativa' que circula en redes comunicacionales del internet y que no hace parte de una política 'viciada' por partidos políticos. 
No entiendo la identificación como una mímesis entre lo visto y el sujeto que ve, sino como un reconocimiento de un sentido de lo creíble que permite una "identificación polimorfa" (Aumont, Bergala, Marie, y Vernet, 1983) que, en nuestro caso, demuestra que no es una identificación con lo homosexual sino con un sentido de valor y cultural-simbólico-, donde la o el espectador(a)/navegador(a)/ciudadano(a) se acomoda en un mejor estatus politico. No se identifica con un sujeto, sino con un instante; un cierto tiempo de la política. En este proceso, las emociones adquieren gran importancia.

El relato también ocurre en la tranquilidad de lo doméstico, y es en este escenario donde se realza y comprende lo privado como un espacio de control de lo familiar, donde este último rasgo fagocita lo problemático de la homosexualidad. El protagonista heterosexual afirma heroicamente: "yo no solo lo defendia porque es gay, sino porque es mi hermano, es mi familia". El otro escenario en este spot es un parque moderno, lejos del ajetreo citadino. El parque, ese lugar de la vida sana, es donde se va a curar a los enfermos: un espacio público ligado a lo saludable. La inclusión de 'lo gay' es parte de esta posibilidad de demostrarnos que somos mejores y más sanos como sociedad. En este sentido es ilustrativa la reflexión de Avital Ronell sobre el VIH en relación con una politica inmunitaria de los cuerpos no-heterosexuales:

Los sanos son tan vulnerables, tan susceptibles a la infección, que deben ser colocados en zonas fuertemente inmunizadas [...] Son tan débiles, o potencialmente débiles, estos sanos que necesitan ser protegidos de la vista de los enfermos; ya que están sometidos a esta forma de contagio visual. (Ronell, 2012, p.38)

Es fundamental reconocer 'lo sano' que quiere representar este video al llevar su testimonio no a la calle, no entre vehículos, no a una marcha, no a un dark-room, sino al Parque Bicentenario ${ }^{7}$, un parque que ansía ser monumento. No olvidemos que las personas homosexuales, en tiempos de liberalismo, deben que olvidarse o no reconocer esa

7 Una de las obras públicas recreativas y áreas verdes más grandes de Santiago, con parques, piscinas y ciclovias, se ubica en la comuna del 'barrio alto' capitalino, la comuna de Vitacura. 
historia de enfermedad (VIH/Sida) que pesa históricamente sobre sus cuerpos. Cabe considerar la advertencia del activista gay y académico David Halperin, para quien:

[...] el liberalismo moderno ha eliminado ciertos modos de dominación solo para producir muchos otros (que no se presentan como modos de dominación y son más difíciles de cuestionar o combatir); ha promovido una ética y un ideal de libertad personal, condicionando el ejercicio de esa libertad a nuevas insidiosas formas de autoridad, a mecanismos de control internalizados. (Halperin, 2007a, p.37)

El 'poco a poco' de la integración tímida integración política de lo homosexual es una lógica expresada en una visualidad que usa el fragmento visual -planos cerrados, cortos y seguidos de los personajes-, como forma de lidiar con el miedo a mostrar 'lo homosexual'; el miedo al desborde.

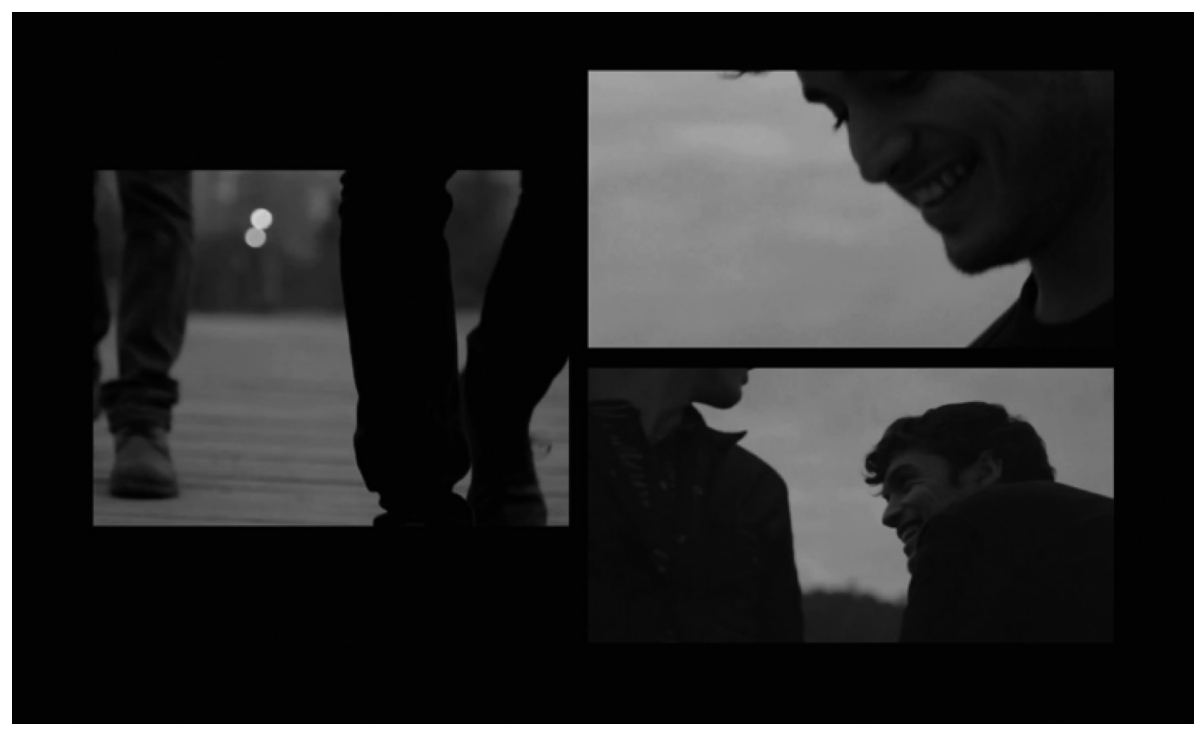

Figura 4. Captura de primeros planos de los spots de la Fundación Iguales.

Montaje y tomas tienen una relación epistemológica en un sentido político no-radical, que asume que, en algún momento, llegaremos a ser mujeres completas o personas gay plenos, afirmando 
una visión -visual y política- evolucionista y lineal. Este spot politico-homosexual no es una producción con excesos de efectos especiales, acciones heroicas y grandes conflictos -quizás lo heroico está en un protagonista masculino que se inscribe como 'salvador' de homosexuales-. Este tipo de dispositivo audiovisual es, más bien, un relato que busca -a través de su puesta en escena y textura audiovisual- parecer lo más cotidiano y común posible. Para ello, es necesario comprender la importancia del dispositivo de visualidad: el celular inteligente (smartphone)

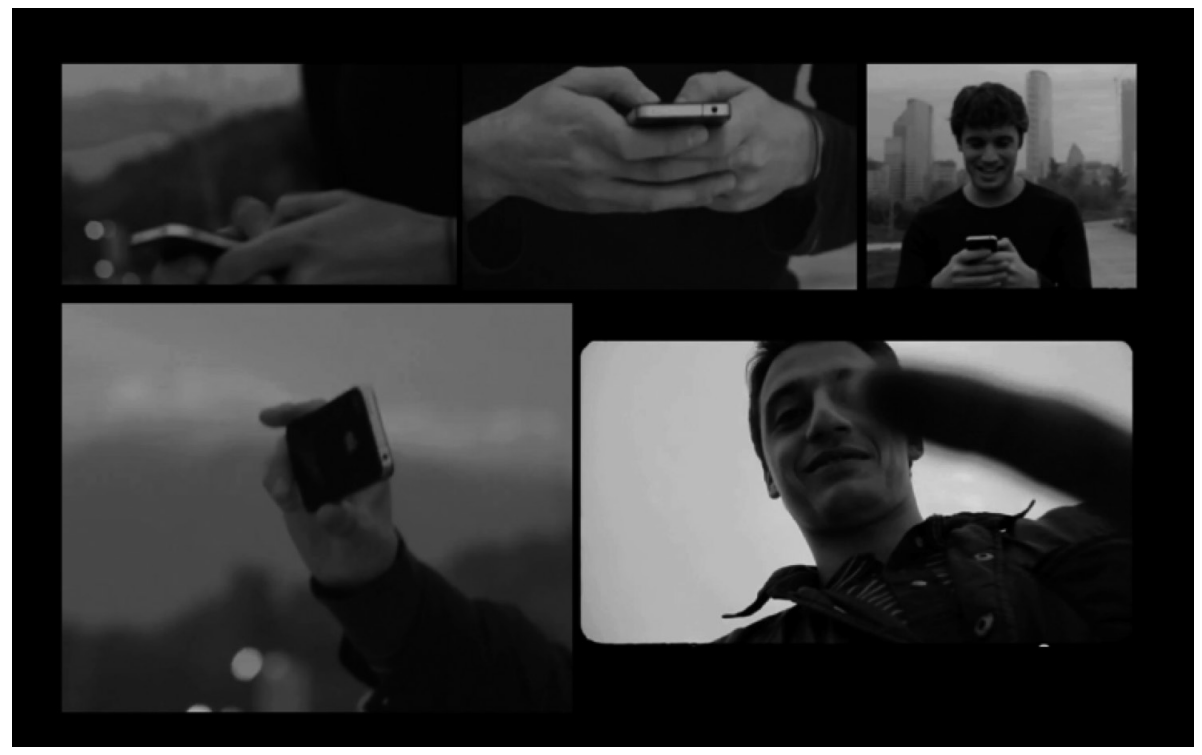

Figura 5. Planos de videos virales de Fundación Iguales con apariciones de celulares.

Estos videos -que simulan ser grabados con celular o cámaras portátiles- son entonces un ejemplo de algo que podríamos denominar, de modo problemático, como audiovisual democrático, porque buscan aparentar y recrear la posibilidad de que cada uno sea protagonista; de que todo ciudadano genere su propio testimonio desde su celular. Cabe recordar que, antes que todo, antes que cualquier rostro, una de las primeras imágenes que vemos en el spot (2012) es un celular registrando lo que sucede, y que otro video-spot de la "Marcha por la Igualdad" empieza con una cámara web registrando el testimonio de una madre que apoya a su hija lesbiana. Esto quiere decir que 
todos pueden hacer parte de la aceptación, que no es otra cosa que la promesa eterna de la democracia; una visualidad que lleva consigo la práctica ideológica-estética de un gesto democratizante.

\title{
El charming gay de la politica ${ }^{8}$ el carisma de la imagen
}

\author{
"¿Qué ocurre si la ley que despliega \\ la figura espectral de la homosexualidad abyecta \\ como una amenaza se convierte \\ en un sitio inadvertido de erotización?"
}

Judith Butler, Cuerpos que importan (2002, p. 148)

Es importante detenerse en las estrategias de reproducción pública de la homosexualidad ciudadana. El ciudadano gay logra seducir la política nacional, instala el matrimonio homosexual como parte del debate obligado de una agenda político-comunicacional chilena, perpetuada por una concertación de partidos de centro-derecha. En el contexto de un país con fuertes niveles de desigualdad y alzamientos de movimientos sociales, a partir de las manifestaciones estudiantiles, cabe preguntarse -estética y políticamente-: ¿Qué es lo que seduce a la politica de lo gay? ¿qué es lo que encanta de estos cuerpos y qué permite su inclusión en el plano de la esfera pública de la política? ${ }^{9}$

8 Tomo el concepto de charming (encantador) del artículo "Charming for the Revolution: a Gaga Manifiesto", de J. Halberstam (2013), donde, en un contexto de producción norteamericana, se analiza la dimensión de encanto e interrupción político cultural que habita en algunas intervenciones de activismos y artes disidentes sexuales y queer. Casos donde, por ejemplo, se valida la seducción que tiene toda acción queer, como las acciones de Pussy Riot (artistas feministas rusas) que, al ingresar con capuchas de colores a una catedral cantando punk contra el presidente, rodean la intervención paródica, política y, a la vez, el peligro de la ilegalidad y la violencia de la ley en una sociedad que, gracias a la difusión virtual y mediática de esta acción, comprueba su incapacidad para imaginar nuevos cuerpos posibles. Las prácticas de emergencia política el caso de las rusas Pussy Riot o incluso Fundación Iguales- siempre estarán cruzadas por una comunicación política que aborda esa seducción, la producción de un carisma de la imagen que, según Halberstam, "habla una gramática visual que no puede ser reducida a un argumento, lo que representa una revolucionaria instancia que [...] nosotros no podemos traducir en palabras".

9 Siguiendo a Wendy Brown (2006) se pone en duda que la ciudadanía gay signifique una 'inclusión' en la politica, ya que estas demandas ciudadanas no generan transformaciones políticas y no aseguran la participación de homosexuales en parlamentos. No, se trata de un simulacro de 


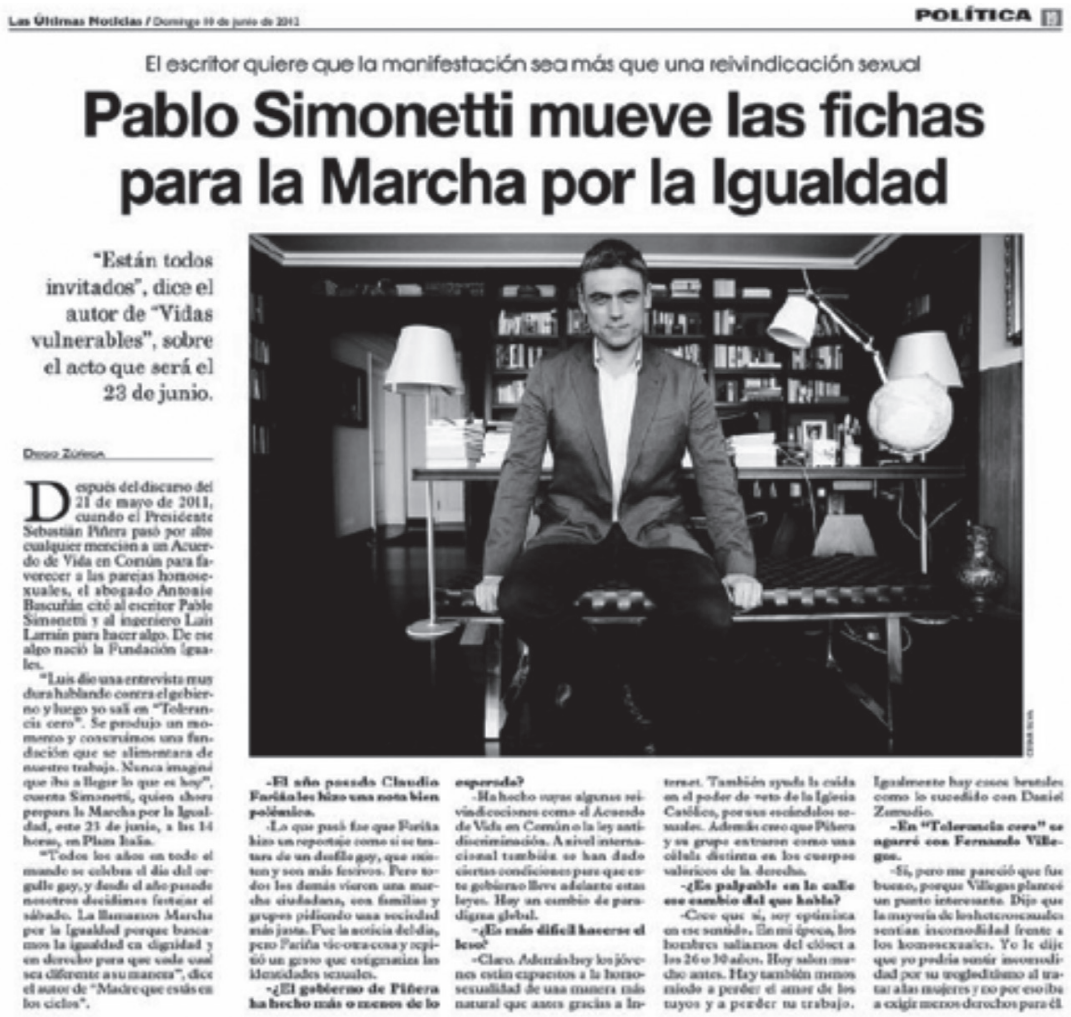

Figura 6. Página del Diario "Las Últimas Noticias"

Pablo Simonetti, presidente de Fundación Iguales, aparece sentado en el escritorio de su cuarto. Pablo -hijo de migrantes italianos- está en su oficina, mirando al espectador a los ojos, sin temor, mostrando confianza y transparencia. El negro, el gris y el blanco componen la gama cromática que ahuyenta todo tipo de feminidad. Él, en su cuarto repleto de libros, manteniendo una figura de sabio,

participación, donde otros modos de participación del Estado acogen las demandas de movimientos homosexuales liberales, pero no se sabe muy bien en qué espacio público. La tolerancia y la nodiscriminación serán los significantes hegemónicos que recorran la política sexual (homosexual) en una segunda etapa de la democracia transicional chilena. "La tolerancia trabaja a lo largo de dos vectores de despolitización -personaliza y naturaliza o simplemente culturaliza- [...] como es usada comúnmente hoy en día la tolerancia tiende a proyectar públicamente los casos de desigualdad o discriminación social como asuntos de un grupo o un individuo particular" (Brown, 2006, p. 15, traducción del autor). 
de joven ilustrado de clase alta, en el lugar donde escribe esas historias de amor, best sellers sobre la vida y el sexo de una elite que tanto interés generan, ¿no es encantador? Pablo, sentado sobre un sofá de cuero sobre un suelo brillante, solo. Todo ordenado. ¿Dónde radica su encanto? ¿Quién hace el aseo? ¿Es su encanto la sexualidad distinta que lo marca, que desborda el significado de la imagen y que marcará y estigmatizará a ese cuerpo? Pablo, con sus manos sobre el cuero, afirmado a un hombre varonil y respetable, ¿acaso no es atractivo? ¿No es provocativo porque esconde algo?

La seducción es parte de la construcción de una imagen liberal de 'lo gay', es una dimensión del deseo estético y masculino que la política hace callar. La seducción hace parte de un proceso erótico de la política neoliberal, donde se busca producir un placer a las audiencias ciudadanas. La pose de Simonetti -varonil, con clase y culto, un hombre con capital sexual- lo hace objeto deseable y posible para una política liberal donde el charming-la posibilidad de encantamiento- se hace muy necesario, en un espacio donde la economía política otorga un valor a los cuerpos gay. Dependerá de lo que diga, haga y represente un sujeto el valor social que obtendrá su cuerpo.

Existe un mercado económico heterosexual donde la "feminidad se devalúa más rápido que la masculinidad" (Preciado, 2008, p.155), esto significa que una mujer queda marginada del valor económico sexual antes que los hombres. Existe una 'relatividad del valor' de las cosas, que "una cosa sea valiosa significa que es valiosa para mí, esto es, que estoy dispuesto a dar algo por ella" (Simmel, 2013, p.84). Se establecen así las dimensiones subjetivas que intervienen la valorización social y económica de los cuerpos y donde la masculinidad, los modos de vida y la juventud de la ciudadanía gay producen su plusvalía socio-económica.

Una de las características más relevantes y reconocidas en términos de construcción político-comunicacional de una política sexual afectiva es la explotación de lo que denominamos charming gay. Tal como señala la palabra inglesa, charming se refiere a un encanto, una seducción generalmente asociada a lo varonil, sino más bien al prototipo del seductor, un estereotipo del 'agente 007'. Stella Bruzzi 
revisa esta producción masculina en su texto Men's Cinema, asumiendo el rol de una construcción audiovisual de la masculinidad en el cine hollywoodense. En una intersección entre gestión de emociones, escenificación individualista de una política sexual liberal y mercantilización de 'lo homosexual', la presentación que el discurso político liberal de la Fundación Iguales hace del homosexual progresista depende y gira en torno al charming gay, donde emociones y sentimientos de la política gay sobresalen en los discursos políticos públicos.

El charming es una cualidad propia del proceso de mediatización del político masculino liberal en la política contemporánea, donde nos enfrentamos a una masculinidad no-conservadora, fresca y liberal, en un contexto de integración de las minorías sexuales, donde la seducción y el acoso sobre estos cuerpos de la política hacen parte de los atributos explotados en el escenario paradójico de una comunicación política despolitizada bajo los discursos de la tolerancia, y una política mercantilizada que criminaliza cualquier disidencia. La figura del 'caballero' (gentlemen) sirve en tanto cumple un rol no conflictivo en la política del respeto.

Se presenta así la construcción masculina del charming, donde se ubica la articulación de una aventura, un cierto heroísmo de esta politica de 'lo homosexual'. Un heroísmo o aventura propia de un sujeto apolítico, no asociado a la política en su engranaje político desvalorado, un personaje que no proviene de una clase política aparentemente tradicional y que, al 'salir del clóset' públicamente, es considerado como una nueva aventura de la política, una nueva posibilidad de ser héroes al soportar los prejuicios familiares y la homofobia del trabajo, y asumir, públicamente, una figura de 'amante'. La aventura y el heroísmo de la construcción del charming gay está en el realce de una 'valentía', la supervivencia de una vida que soportó la violencia homofóbica, un valor para la justicia en esta visibilidad política, una victoria político-sexual más privada que pública y que es, más bien, parte de una terapia psicológica mediatizada. Así lo expresa la siguiente entrevista al líder de esta ciudadanía gay, transmitida en el programa matinal Buenos Días a Todos, en junio de 2011: 
FELIPE CAMIROAGA: ¿Te costó Pablo [Simonetti] planteárselo a tus viejos, a tu familia?

PABLO SIMONETTI: Me costó muchísimo, tenía miedo a perderlos, tenía miedo a perder mi pertinencia, tenía miedo a perder mis amigos, mis redes, la sensación de seguridad que todo eso te da. Yo se los plantee porque estaba enamorado, por primera vez...

FELIPE CAMIROAGA: ¿Te acuerdas de esa conversación?

PABLO SIMONETTI: Yo me acuerdo perfectamente de la conversación que tuve con mi madre, sí, fue una conversación muy emotiva, muy emocionante y claro yo creo que en el principio les produjo mucho dolor, pero en cambio con el tiempo todo se supera y eso es lo bonito de hablar, de salir afuera y decir, mira esto es lo que me ocurre, yo soy así, soy tu mismo hijo, el mismo que estaba sentado ayer y hoy en tu mesa, simplemente que te estoy relevando algo de mi intimidad, que me denota, que me marca, que me concierne, pero eso no hace que yo sea otra persona $[\ldots]$

La valentía psicológica se refiere a la capacidad de sobrellevar y no dejarse doblegar por los malestares psicológicos que padecería el sujeto homosexual descrito. Esta valentía se realza al describir una violencia internalizada, referida a una fase juvenil o adolescente. Es un llamado ideológico de un discurso político y una estrategia comunicacional que apela a la integración a través de un discurso de aceptación.

El charming gay se potencia con su carácter apolítico, no partidista y no conflictivo, y gracias al ingreso, en formas visuales, en dimensiones de lo privado, propio de la narrativa en tiempo pasado de la exhibición política de la ciudadanía homosexual. Esto permite explotar un encanto maternal político de un líder carismático como Pablo Simonetti; un deseo maternal por proteger a un otro sexual desvalido. Simonetti, como otros líderes de la Fundación Iguales, poseen ese inofensivo y atractivo charming que la política actual requiere, un charming que es beneficioso para la política porque no es una figura violenta ni confusa, sino atractiva y seductora para la audiencia ciudadana en Chile. 


\section{Conclusión: La privatización de la imagen sexual}

En esta investigación se analizaron los usos que la comunicación politica hace del significante gay, para explicar la plusvalía que esta sexualidad adquiere en tiempos de derecha. A través de distintos dispositivos y fragmentos de la comunicación viralizados en internet, redes sociales y televisión, se describió un modo liberal de producir una subjetividad político-sexual: traumas, miedos, ideales y estrategias políticas son descritos como ejes que funcionan como el marco de las visualidades de lo gay liberal (Butler, 2010; Chihu, 2010).

A falta de una articulación social, el liberalismo facilita estrategias de comunicación para generar una política virtual que contenga una ciudadanía gay. Al mismo tiempo, estos contenidos son compartidos en redes sociales, también denominadas "tecnologías de la proximidad" (Reguillo, 2012), donde cada usuario comparte contenidos que generan redes de amistad político-social. Así, en "la interface Youtube/ Facebook, no se comparte solamente la música, sino además una clave de lectura que la o el posteador propone a sus interlocutores o 'amigos"' (Reguillo, 2012). Las redes sociales median la comunicación de la política gay donde implícitamente se construye la imposibilidad de rechazar estos contenidos, ante la obligatoriedad de una ciudadanía virtual rápidamente amistosa con el ciudadano gay. Esta subjetividad liberal, que hace ingresar 'lo gay' virtualmente en el espacio politico, olvida y omite las historias de violencia estatal, social y política que -al igual que con otras víctimas cuyos derechos humanos no han sido reconocidos- aún constituyen a las personas no-heterosexuales en Chile. Este aún es muy importante, ya que la discusión pública de lo gay, especialmente el modo de puesta en escena respetuoso y tolerante, busca instalar la idea de que, en Chile, el tiempo de la tortura contra gays y lesbianas "ya fue", "ya pasó".

La homosexualidad liberal aspira a la formación de la familia y a la constitución del hogar, y aspira a poseer la dimensión de lo privado-intimo. Es justamente lo contrario a lo que articuló el feminismo del norte a mediados del siglo XX, desde el cual se entendió que "el paraíso doméstico funcionaba como una arquitectura penitenciaria en 
la que las mujeres eran encerradas de por vida y mantenidas a distancia de la esfera política" (Preciado, 2010, p. 49). Estos spots de la Fundación Iguales visibilizan una etapa 'primaria' e inicial de emancipación, ejercida en la intimidad y el espacio privado, precisamente porque lo homosexual, si fuera asociado a la dimensión del trabajo, sería incluso más problemático. Esta ubicación de lo político homosexual a través de la visualidad de la Fundación Iguales está ligado y coincide con un tópico económico y político contemporáneo de "politización y mercantilización de la vida privada” (Preciado, 2010, p.43).

A modo de conclusión política y ética, sugiero que esta vuelta de página de las representaciones del odio homofóbico y la omisión de la violencia actual contra las comunidades homosexuales es uno de los hallazgos político-comunicacionales más preocupantes ante la inclusión liberal de 'lo gay'. Nadie nos asegura, y menos todavía con estas representaciones light de lo sexual en tiempos de derecha, que no vendrá una ola homofóbica en Latinoamérica en contra de 'lo gay'. En este panorama, urge abogar por hacer visible al homosexual no como víctima, sino a las violencias y daños cotidianos sociales que generan las desigualdades de las comunidades de gay, lesbianas y transexuales. El ciudadano gay es una figura que da vuelta a la página en la política, que presenta 'nuevos' desafios y es encantadoramente nuevo para nuestra democracia, y que quiere desentenderse de las huellas de un pasado que pesa sobre sus cuerpos.

Rescato el concepto de simulación utilizado por Pecheny (2002) para describir la protección de la representación social de las personas gay para evitar ser discriminados. Como grupo social y politico, anteponen el lugar de la defensa y la protección para evitar ser discriminados. Esto implica regular sus representaciones bajo modelos de vida liberal y privatizada. Reconocer cómo una agenda familiar se vincula a la representación y a los discursos político comunicacionales es un carácter cualitativo que intenta asegurar la no conflictividad de 'lo gay', ya que se hace visible mediante el respeto de las formas de una heterosexualidad que instala a la familia como un lugar protagónico. Las sociedades homofóbicas obligan a mantener en secreto estas sexualidades. Hay "tolerancia a cambio de la discreción y 
la invisibilidad" (Pecheney, 2002). Se separan las esferas públicas y privadas y se privatiza lo público. Porque el ciudadano gay ocupa las calles, pero de un modo 'privado', en secreto. No se quiere más burla, sino más bien una homosexualidad correcta y obediente.

Respecto al cuerpo escenificado en una imagen afectiva, es importante en tanto que es el territorio donde se expresan afectos, gestos y posiciones públicas. Se concluye que 'lo homosexual', en Chile, tiene un lugar donde la identidad gay política es más legitimada en tanto se exprese la afectuosidad amorosa que la regula. Son estos valores familiares y afectivos los que edulcoran los conflictos politicos. Hay un particular trato de la política con lo gay liberal, a diferencia de otras corporalidades excluidas del campo político y que luchan por algún tipo de inclusión. Un trato especial y más afectivo que se corresponde con representaciones de este 'nuevo trato' liberal hacia lo gay, que no es, paradójicamente, más lastimero o victimizante, siendo que no busca inferiorizar o insultar estereotípicamente unas vidas, sino que resuelve privatizar esta sexualidad, darle un lugar específico, un derecho a vivienda simbólica en el terreno de la esfera política. Esto se evidencia en los spots políticos, donde el sujeto homosexual está resguardado en su cuarto propio y en el afecto de su familia, y en las politicas pro matrimonio gay que insisten en legitimar y relevar instituciones que privatizan la sexualidad en la seguridad de un cuarto propio familiar.

Dado que el discurso de la igualdad se materializa en ciertas figuraciones privatizadas de la ciudadanía gay, es relevante escuchar esa resistencia a la homogenización que propone este modo de la política sexual liberal. ¿Es posible ser un igual en el sur? ¿Es posible ser tratado como un igual en ese escenario? La pregunta cobra aún más importancia cuando

[...] las identidades LGTTTBIQ se transforman en existencias enlatadas listas para consumir, o en lockers de fronteras lindantes con la mismidad, o que se diluyen bajo una retórica pudorosa, conservadora, que asépticamente desexualiza la diversidad al despojarla de su cualidad de 'sexual'. (Flores, 2013, p. 315) 
Como cuestionaba ya Wendy Brown (2006) a partir de análisis de casos norteamericanos, la tolerancia es un discurso problemático porque, más que acercar, distancia una experiencia sexual en el plano político, al privatizar un género e inmunizar la sobreprotección normativa de estas sexualidades. En Chile, este discurso público de la tolerancia se traduce y se impone en la narrativa política -adecuándose muy bien con los 'consensualismos' democráticos y anti-antagonismos sociales-y se traduce en un lenguaje comunicacional político que se sobre-recoge y cuida al momento de referirse a la ciudadanía gay.

"Cuando lo común-comunitario se ve sacrificado por la compulsión privatizadora de una economía de mercado", señala Richard (2013), desde Chile, en una reflexión que hace explícito el rol del carisma o charming del género en la figura de la presidenta Michelle Bachelet: "la disposición anímica de la sociedad puede volcarse hacia los 'afectos' de lo femenino para rehumanizar lo que deshumanizó la tecnicidad de lo político-administrativo" (Richard, 2013, p. 206). Concordamos con el rol de los afectos en esta rehumanización, que se expresa en la activación ciudadana que propone el sujeto político gay, donde lo femenino es muy importante en la seducción. Sobresale así el rol de los afectos y las emociones de los cuerpos sexuales en estas imágenes de propaganda política. El sentido afectivo, amoroso y seductor de la imagen política del ciudadano gay hace visible la operación de las emociones en el éxito social de esta política gay, más blanqueada y apegada a valores nacionales y liberales, donde la familia privada es lo más importante.

\section{Referencias}

Amigo, B., Bravo, M. y Osorio, F. (2014, diciembre). Telenovela, recepción y debate social. Cuadernos.info. (35), 135-145.

Aumont, J., Bergala, A., Marie, M. y Vernet, M. (1983). Estética del Cine. Espacio filmico, montaje, narración, lenguaje. Barcelona: Editorial Paidós. 
Bal, M. (2003, abril). El esencialismo visual y el objeto de los estudios visuales. Journal of Visual Culture, 2(1), 5-32.

Blanco, F. (2013). Queer Latinoamérica: ¿cuenta regresiva? En Falconi, D., Castellanos, S., y Viteri, M. (Eds.). Resentir lo queer en América Latina. Diálogos desde/con el Sur (pp. 27-43). Barcelona: Egales.

Brown, W. (2006). Regulating Aversion. Tolerance in the Age of identity an Empire. New Jersey: Princenton University Press.

Bruzzi, S. (2008). Men's Cinema. London: Wallflower Press.

Butler, J. (2002). Cuerpos que importan. Sobre los limites materiales y discursivos del "sexo". Buenos Aires: Editorial Paidós.

Butler, J. (2010). Marcos de Guerra. Vidas Lloradas. Buenos Aires: Editorial Paidós.

Chihu, A. (2010). El framing del spot politico. México D.F.: Universidad Autónoma Metropolitana, Unidad Iztapalapa.

Curia, D. (2013, septiembre 12). Espejitos de colores. Entrevista a Jane Bennett. Página 12. Suplemento Soy. Recuperado de http://www.pagina12.com.ar/ diario/suplementos/soy/1-3092-2013-09-14.html

De Lauretis, T. (1992). Alicia ya no. Feminismo, semiótica y cine. Madrid: Ediciones Cátedra.

Flores, V. (2013). Interrupciones. Ensayos de poética activista. Neuquén: Editora La Mondonga Dark.

Fundación Iguales (2012, junio 11). Spot Marcha de la Igualdad [web log post]. Recuperado de http://www.youtube.com/watch?v=v4zGA3-B83E

Galindo, M. (2014). Feminismo urgente. ¡A despatriarcar! La Paz: Editorial Lavaca. 
Garretón, M. (2012). Neoliberalismo corregido y progresismo limitado. Los gobiernos de la Concertación en Chile. 1990-2010. Santiago: Colección Pensar América Latina, Editorial ARCIS/ CLACSO.

Grau, O. (2011). Por el lugar de los intersectos o de las subjetividades en intersección. En Colectivo Universitario de Disidencia Sexual (Ed.). Por un feminismo sin mujeres (pp. 45-55). Santiago: Editorial Territorios Sexuales Ediciones.

Halberstam, J. (2012). Gaga Feminism: Sex, Gender, and the End of Normal. Boston: Beacon Press.

Halberstam, J. (2013, abril). Charming for the Revoluction: a Gaga Manifiesto. E-flux, (44). Recuperado de http:/ / www.e-flux.com/journal/charming-for-therevolution-a-gaga-manifesto/

Halperin, D. (2007a). San Foucault. Para una hagiografía gay. Córdoba: Ediciones literales, Córdoba.

Halperin, D. (2007b, octubre). ¿Qué quieren los hombres gays?. Sexo riesgo y la vida subjetiva de la homosexualidad. Debate Feminista, 18(36), 273-288

Mouffe, C. (1999). El retorno de lo politico. Comunidad, ciudadanía, pluralismo y democracia radical. Buenos Aires: Paidós.

Pecheny, M. (2002). Identidades discretas. En Arfuch, L. (Comp.) Identidades, sujetos y subjetividades (pp.125-148). Buenos Aires: Prometeo libros.

Preciado, B. (2008). Testo Yonqui. Madrid: Espasa.

Preciado, B. (2010). Pornotopía. Arquitectura y sexualidad en "Playboy" durante la guerra fría. Barcelona: Anagrama.

Puar, J. (2007). Terrorist assemblages. Homonationalism in queer times. Durham: Duke University Press. 
Reguillo, R. (2012, julio-diciembre). Navegaciones errantes. De músicas, jóvenes y redes: de Facebook a Youtube y viceversa. Nueva época, (18), 135-171.

Richard, N. (1998). Residuos y metáforas (Ensayos de critica cultural sobre el Chile de la Transición). Santiago: Editorial Cuarto Propio.

Richard, N. (2013). Crítica y Politica. Santiago: Palinodia.

Ronell, A. (2012). Reinas de la noche. Santiago: Editorial Palinodia.

Rosler, M. (2007). Imágenes públicas. La función política de la imagen. Barcelona: Editorial Gustavo Gili.

Ruiz, C., \& Boccardo, G. (2013). Peripecias del capital y el trabajo en el “neoliberalismo avanzado". Revista Análisis del Año 2012. Política, Sociedad y Economía. (15), 25-52.

Sabsay, L. (2011). Fronteras sexuales: espacio urbano, cuerpos, ciudadanía. Buenos Aires: Paidós.

Simmel, G. (2013). Filosofía del dinero. Madrid: Capitán Swing.

Zizek, S. (2007). El acoso de las fantasías. Ciudad de México: Ed. Siglo XXI.

\section{Cómo citar este artículo}

Cabello-Valenzuela, C. (2016). No hay cuerpo sin imagen. Visualidad gay y politica virtual en tiempos liberales. Universitas Humanística, 81, 59-87. http:// dx.doi.org/10.11144/Javeriana.uh81.ncsi 